\title{
Impact of DPP-4 inhibitors on plasma levels of BNP and NT-pro-BNP in type 2 diabetes mellitus
}

Liying Muํ', Zhuo Wang ${ }^{2}$, Jinmei Ren ${ }^{3}$, Xiaowei Xiong ${ }^{1}$, Zening Jin ${ }^{1,5^{*}}$ and Xin Liu ${ }^{4^{*}}$

\begin{abstract}
Background: Dipeptidyl peptidase-4 inhibitors (DPP-4i) decrease glucose levels by regulating incretin peptides in type 2 diabetes mellitus (T2DM). This study aimed to determine the modulatory effect of DPP-4i on brain natriuretic peptide (BNP) and N-terminal pro-brain natriuretic peptide (NT-pro-BNP) in patients with T2DM.

Methods: PubMed, Embase and the Cochrane Library were systematically searched to identify randomized controlled trials (RCTs) evaluating the impact of DPP-4i on BNP or NT-pro-BNP. A fixed- or random-effects model was used for quantitative analysis, according to the heterogeneity. Sensitivity analysis and publication bias were performed using standard methods.

Results: Nine trials with 3056 patients with T2DM were included. Meta-analysis revealed that DPP-4i did not signifcantly modulate the BNP $(0.21 \mathrm{pg} / \mathrm{mL}, 95 \% \mathrm{Cl}-2.36-2.79)$ or NT-pro-BNP level $(-7.34 \mathrm{pg} / \mathrm{mL}, 95 \% \mathrm{Cl}-24.27-9.59)$. DPP-4i demonstrated no stronger effect on modulating BNP $(5.17 \mathrm{pg} / \mathrm{mL}, 95 \% \mathrm{Cl}-7.48-17.82)$ or NT-pro-BNP $(-9.95 \mathrm{pg} / \mathrm{mL}, 95 \% \mathrm{Cl}-44.61-24.71)$ than active comparators. Pooled analysis was robust and stable after sensitivity analysis.
\end{abstract}

Conclusions: DPP-4i exhibits no significant effect on modulating BNP or NT-pro-BNP and shows no stronger effect than traditional antidiabetic agents in T2DM.

Keywords: Dipeptidyl peptidase-4 inhibitors, BNP, NT-pro-BNP, Type 2 diabetes mellitus, Randomized controlled trials

\section{Introduction}

Dipeptidyl peptidase-4 inhibitors (DPP-4is) have been developed as oral antidiabetic agents in type 2 diabetes mellitus (T2DM), as they prevent the degradation of incretins such as glucagon-like peptide 1 (GLP-1) and glucose-dependent insulinotropic polypeptide (GIP) [1]. DPP-4is have a favorable effect on lowering glucose levels without increasing the risk of hypoglycemia or weight

\footnotetext{
*Correspondence: jinzeningttyy@163.com; liuxinmj@aliyun.com

${ }^{4}$ Department of Pharmacy, Beijing Tiantan Hospital, Capital Medical University, Beijing, China

${ }^{5}$ Department of Cardiology and Macrovascular Disease, Beijing Tiantan Hospital, Capital Medical University, Beijing, China

Full list of author information is available at the end of the article
}

gain [2]. However, in the past 2 decades, cardiovascular safety issues have been taken into consideration for antidiabetic agents since reports about the increased risk of cardiovascular outcomes with rosiglitazone [3].

In fact, the Food and Drug Administration (FDA) stated that new agents for treating T2DM must have been tested for cardiovascular safety in clinical trials [4]. Therefore, DPP-4is have been studied in a seriouscardiovascular-outcome trial. According to its results, different DPP-4is had different effects on cardiovascular events. Like linagliptin, sitagliptin had neutral cardiovascular aspects, and alogliptin in the EXAMINE trial did not demonstrate a beneficial effect [5]. Saxagliptin in the SAVOR-TIMI 53 trial even showed a higher risk of hospitalization for heart failure [6]. Therefore, clinicians face original author(s) and the source, provide a link to the Creative Commons licence, and indicate if changes were made. The images or other third party material in this article are included in the article's Creative Commons licence, unless indicated otherwise in a credit line to the material. If material is not included in the article's Creative Commons licence and your intended use is not permitted by statutory regulation or exceeds the permitted use, you will need to obtain permission directly from the copyright holder. To view a copy of this licence, visit http://creativecommons.org/licenses/by/4.0/. The Creative Commons Public Domain Dedication waiver (http://creativeco mmons.org/publicdomain/zero/1.0/) applies to the data made available in this article, unless otherwise stated in a credit line to the data. 
confusing information as to how to select a suitable DPP4i for treating T2DM patients with high cardiovascular risk.

There are substrates of DPP-4 beyond glucagon-like peptides that have been proven to have cardiovascular effects, such as brain natriuretic peptide (BNP) [7]. $\mathrm{BNP}$ and N-terminal pro-brain natriuretic peptide (NTpro-BNP) are released as products of cardiomyocytes in cardiovascular disease. They have been recognized as valuable biomarkers for heart failure in clinical practice [8]. Since no association between BNP or NT-pro-BNP and DPP-4is in T2DM has been established, the current meta-analysis was performed to identify the impact of DPP-4is on BNP and NT-pro-BNP in type 2 diabetes.

\section{Methods}

\section{Literature search strategy}

This meta-analysis was conducted according to the Preferred Reporting Items for Systematic Reviews and MetaAnalysis (PRISMA) guidelines [9]. We searched PubMed, Embase and the Cochrane Library for randomized controlled trials (RCTs) with the key words "sitagliptin" OR "vildagliptin" OR "teneligliptin" OR "saxagliptin" OR "linagliptin" OR "alogliptin" from inception to April 30, 2021. The search was limited to human studies, and no language restriction was applied. Two authors independently performed the search by applying the inclusion and exclusion criteria and extracted the data from the retrieved studies.

\section{Study selection}

Two authors independently reviewed studies based on the titles, abstracts, and keywords to ensure that no relevant study was missed. Eligible studies met all the following criteria: (1) randomized controlled studies comparing DPP-4is with placebo or other diabetic medication; (2) studies with information on BNP or NT-pro-BNP levels at baseline and at the end of follow-up in each group or providing the net change values; and (3) studies conducted in patients with T2DM. The exclusion criteria were as follows: (1) studies conducted in healthy volunteers; (2) studies not in humans; (3) narrative reviews or abstracts; and (4) studies that did not provide data on the levels of BNP or NT-pro-BNP at baseline or at the end of follow-up. The inclusion and exclusion criteria were evaluated objectively by two reviewers. The reference lists of eligible articles were hand-searched, and corresponding authors were contacted if relevant information was missing.

\section{Data extraction}

Two reviewers extracted the data and entered them into a designed form. Detailed information was listed, including first author, publication year, country origin, sample size, ratio of men to women, body mass index, mean age, diabetes duration, medication intervention, therapy duration and serum BNP/NT-pro-BNP concentrations at baseline. In studies with different treatment durations, the longest therapy duration was extracted for statistical analysis. The primary outcome measure was a net change in the BNP/NT-pro-BNP concentrations.

\section{Quality evaluation}

Study quality was evaluated according to the Cochrane Reviewers' Handbook. The items used for the evaluation of each study included random sequence generation, allocation concealment, blinding of participants and personnel, blinding of outcome assessment, incomplete outcome data, selective outcome reporting, and other potential sources of bias. According to the Cochrane Handbook, a judgment of 'yes' indicated a low risk of bias, whereas 'no' indicated a high risk of bias. Labeling an item as 'unclear' indicated an unknown or unclear risk of bias. Disagreements were resolved by discussion with a third author.

\section{Statistical analysis}

Continuous data were pooled with a fixed-effects or random-effects model, according to the study heterogeneity. Data for BNP/NT-pro-BNP at the final follow-up evaluation were analyzed. Heterogeneity was quantitatively assessed with the $I^{2}$ index. Effect sizes are reported as weighted mean differences (WMDs) and confidence intervals (CIs). Sensitivity analysis was conducted with the leave-one-out method to evaluate the influence of each study on the overall effect size. Potential publication bias was explored using Begg's test and Egger's test if there were at least five studies in the meta-analysis. Subgroup analysis was performed according to treatment duration, BMI and HbA1c at baseline. Statistical calculations for the meta-analysis were performed using RevMan 5.3 and STATA version 13.0.

\section{Results}

\section{Flow of included studies}

We identified 8690 published articles after systematic searching. After removal of inadequate studies, a total of 9 studies providing data for 6056 patients met the review eligibility criteria [10-18]. Of these patients, 3037 were treated with a DPP-4 inhibitor (222 with sitagliptin, 2701 with alogliptin, 68 with vildagliptin and 46 with linagliptin) in monotherapy or in addition to metformin or another antidiabetic agent, and 3019 were treated with placebo or control therapy. The flowchart of inclusion and exclusion is shown in Fig. 1. 


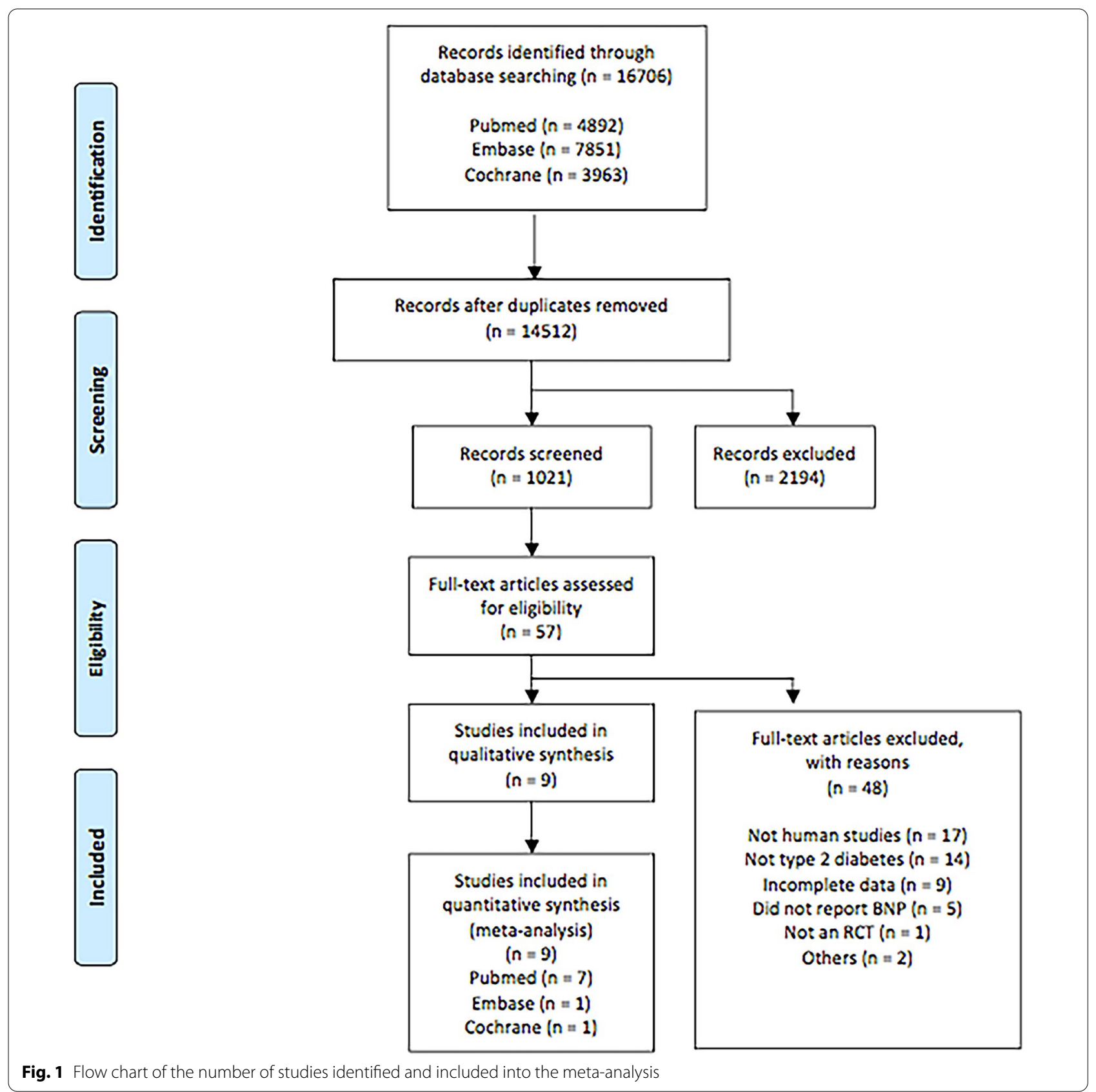

\section{Characteristics of included studies}

The characteristics of the included studies are presented in Table 1. These studies were published between 2015 and 2019. BNP and NT-pro-BNP were monitored in one study conducted by Fadini et al. [13]. Two studies evaluated the changes in BNP [11] and NT-pro-BNP [12], respectively, between patients treated with sitagliptin and those treated with active drugs, using three treatment arms. Out of the 9 studies, 4 set placebo as the control. Follow-up time ranged from 0.5 to 48 months. In the largest study, 5380 subjects were included, while the smallest study enrolled 20 subjects. Most of the studies compared sitagliptin with placebo or traditional antidiabetic agents. Active drugs or traditional antidiabetic agents discussed in this study included metformin, liraglutide, glargine, voglibose, glimepiride and dapagliflozin. 
Table 1 Demographic characteristics of the studies included

\begin{tabular}{|c|c|c|c|c|c|c|c|c|c|}
\hline Study, year & Location & $\begin{array}{l}\text { Treatment } \\
\operatorname{arm}(\mathrm{n})\end{array}$ & HbA1c (\%) & Male (n) & Age (years) & $\mathrm{BMI}\left(\mathrm{kg} / \mathrm{m}^{2}\right)$ & $\begin{array}{l}\text { Diabetes } \\
\text { duration } \\
\text { (years) }\end{array}$ & $\begin{array}{l}\text { Treatment } \\
\text { duration } \\
\text { (months) }\end{array}$ & $\begin{array}{l}\text { BNP/NT-pro- } \\
\text { BNP (pg/mL) }\end{array}$ \\
\hline Oe, 2015 [10] & Multicentre & $\begin{array}{l}\text { sita: } 40 \\
\text { vog:40 }\end{array}$ & $\begin{array}{l}7.1 \pm 0.7 \\
6.9 \pm 0.5\end{array}$ & $\begin{array}{l}30 \\
21\end{array}$ & $\begin{array}{l}67.8 \pm 10.5 \\
66.7 \pm 9.8\end{array}$ & $\begin{array}{l}27.7 \pm 4.1 \\
25.7 \pm 4.3\end{array}$ & $\begin{array}{l}4.0 \pm 1.8 \\
3.2 \pm 1.5\end{array}$ & 6 & $\begin{array}{l}39.0 \pm 38.0 \\
34.0 \pm 35.0\end{array}$ \\
\hline $\begin{array}{l}\text { Hiramatsu, } \\
2018 \text { [11] }\end{array}$ & Japan & $\begin{array}{l}\text { sita:34 } \\
\text { lina:32 } \\
\text { lira:32 }\end{array}$ & $\begin{array}{l}6.7 \pm 0.7 \\
6.7 \pm 0.7 \\
6.7 \pm 0.6\end{array}$ & NS & $\begin{array}{l}69.9 \pm 8.5 \\
69.0 \pm 7.7 \\
70.5 \pm 5.7\end{array}$ & $\begin{array}{l}24.2 \pm 3.8 \\
23.8 \pm 4.8 \\
23.5 \pm 3.5\end{array}$ & $\begin{array}{l}8.3 \pm 8.3 \\
8.3 \pm 0.4 \\
9.2 \pm 7.0\end{array}$ & 48 & $\begin{array}{l}83.9 \pm 59.2 \\
90.6 \pm 68.6 \\
91.6 \pm 69.9\end{array}$ \\
\hline $\begin{array}{l}\text { Arturi, } 2016 \\
{[12]}\end{array}$ & Italy & $\begin{array}{l}\text { sita:10 } \\
\text { lira:10 } \\
\text { glar:12 }\end{array}$ & $\begin{array}{l}8.3 \pm 0.9 \\
8.2 \pm 1.0 \\
7.9 \pm 0.8\end{array}$ & $\begin{array}{l}6 / 10 \\
7 / 10 \\
9 / 12\end{array}$ & $\begin{array}{l}60.5 \pm 10 \\
59.5 \pm 9 \\
60 \pm 8\end{array}$ & $\begin{array}{l}30.9 \pm 2.8 \\
33.2 \pm 2.0 \\
30.8 \pm 6.0\end{array}$ & NS & 13 & $\begin{array}{l}293.0 \pm 46.0 \\
310.0 \pm 62.0 \\
296.0 \pm 60.0\end{array}$ \\
\hline $\begin{array}{l}\text { Fadini, } 2017 \\
\text { [13] }\end{array}$ & Italy & $\begin{array}{l}\text { lina:22 } \\
\text { pla:24 }\end{array}$ & $7.6 \pm 0.2$ & $33 / 46$ & $63.7 \pm 1.3$ & $31.1 \pm 0.7$ & NS & 0.5 & $101.0 \pm 93.2$ \\
\hline $\begin{array}{l}\text { Kitao, } 2017 \\
{[14]}\end{array}$ & Multicentre & $\begin{array}{l}\text { vild:48 } \\
\text { met:48 }\end{array}$ & $\begin{array}{l}7.3 \pm 0.6 \\
7.6 \pm 1.1\end{array}$ & $\begin{array}{l}26 / 48 \\
31 / 48\end{array}$ & $\begin{array}{l}62.0 \pm 14.3 \\
60.0 \pm 18.0\end{array}$ & $\begin{array}{l}25.7 \pm 4.1 \\
26.1 \pm 4.7\end{array}$ & $\begin{array}{l}5.4 \pm 3.5 \\
6.5 \pm 3.5\end{array}$ & 3 & $\begin{array}{l}31.0 \pm 96.0 \\
26.0 \pm 68.0\end{array}$ \\
\hline $\begin{array}{l}\text { Nomoto, } 2016 \\
\text { [15] }\end{array}$ & Multicentre & $\begin{array}{l}\text { sita:48 } \\
\text { glim:55 }\end{array}$ & $\begin{array}{l}7.4 \pm 0.6 \\
7.4 \pm 0.4\end{array}$ & $\begin{array}{l}33 \\
29\end{array}$ & $\begin{array}{l}62.0 \pm 15.0 \\
60.0 \pm 8.0\end{array}$ & $\begin{array}{l}25.7 \pm 3.9 \\
25.2 \pm 3.5\end{array}$ & NS & 6.5 & NS \\
\hline $\begin{array}{l}\text { Phromminti- } \\
\text { kul, } 2019 \text { [16] }\end{array}$ & Thailand & $\begin{array}{l}\text { vild:24 } \\
\text { dapa:25 }\end{array}$ & $\begin{array}{l}8.2 \pm 1.2 \\
8.1 \pm 1.4\end{array}$ & $\begin{array}{l}12 \\
11\end{array}$ & $\begin{array}{l}63.9 \pm 7.6 \\
62.6 \pm 8.3\end{array}$ & $\begin{array}{l}24.9 \pm 3.2 \\
25.6 \pm 3.0\end{array}$ & $>5$ & 6 & $\begin{array}{l}955.8 \pm 1853.7 \\
399.9 \pm 493.1\end{array}$ \\
\hline $\begin{array}{l}\text { Yamada, } 2017 \\
{[17]}\end{array}$ & Multicentre & $\begin{array}{l}\text { sita:55 } \\
\text { con: } 60\end{array}$ & $\begin{array}{l}7.0 \pm 0.6 \\
6.9 \pm 0.5\end{array}$ & $\begin{array}{l}38 / 55 \\
39 / 60\end{array}$ & $\begin{array}{l}69.0 \pm 8.0 \\
69.0 \pm 9.0\end{array}$ & $\begin{array}{l}25.9 \pm 3.3 \\
24.8 \pm 3.9\end{array}$ & NS & 24 & $\begin{array}{l}111.5 \pm 66.2 \\
99.6 \pm 60.9\end{array}$ \\
\hline $\begin{array}{l}\text { Zannad, } 2015 \\
\text { [18] }\end{array}$ & Multicentre & $\begin{array}{l}\text { alog:2701 } \\
\text { pla:2679 }\end{array}$ & $\begin{array}{l}8.12 \pm 1.12 \\
8.15 \pm 1.12\end{array}$ & $\begin{array}{l}1637 / 2701 \\
1631 / 2679\end{array}$ & $\begin{array}{l}63.0 \pm 4.7 \\
62.0 \pm 5.0\end{array}$ & $\begin{array}{l}29.7 \pm 2.5 \\
29.5 \pm 2.6\end{array}$ & $\begin{array}{l}7.9 \pm 13.0 \\
6.8 \pm 16.1\end{array}$ & 5 & $\begin{array}{l}699.0 \pm 500.7 \\
630.0 \pm 472.7\end{array}$ \\
\hline
\end{tabular}

Values are expressed as mean $\pm S D$.

$n$ number of participants per group; HbA1c glycated haemoglobin; sita sitagliptin; alog alogliptin; vild vildagliptin; lina linagliptin; met metformin; pla placebo; con conventional treatment; lira liraglutide; glar glargine; vog voglibose; glim glimepiride; dapa dapagliflozin; NS not stated

\section{Quality evaluation}

Studies qualities were evaluated according to the scheme indicated by the Cochrane criteria. There was no unclear risk of bias in the studied items. All the studies had a randomized designed. Details on the items and their bias criteria across the studies are displayed in Fig. 2. Seven studies had performance bias due to the absence of blinding methods, whereas three studies had detection bias based on blinding of outcome assessment.

\section{Meta-analysis of the effect of DPP-4i treatment}

The pooled analysis of the effect of DPP-4is on BNP levels yielded a difference of $0.21 \mathrm{pg} / \mathrm{mL}(95 \% \mathrm{CI}-2.36-2.79$,

Random sequence generation (selection bias)

Allocation concealment (selection bias)

Blinding of participants and personnel (performance bias)

Blinding of outcome assessment (detection bias)

Incomplete outcome data (attrition bias)

Selective reporting (reporting bias)

Other bias

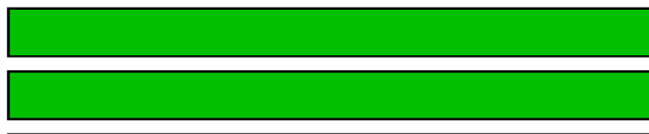

L

$\square$

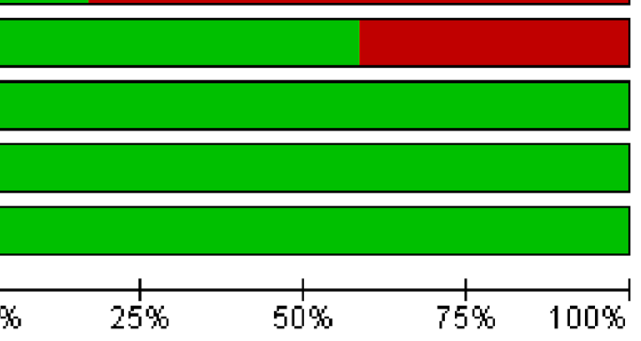

Low risk of bias

Unclear risk of bias

High risk of bias

Fig. 2 Risk of bias assessment in the studies identified for meta-analysis 


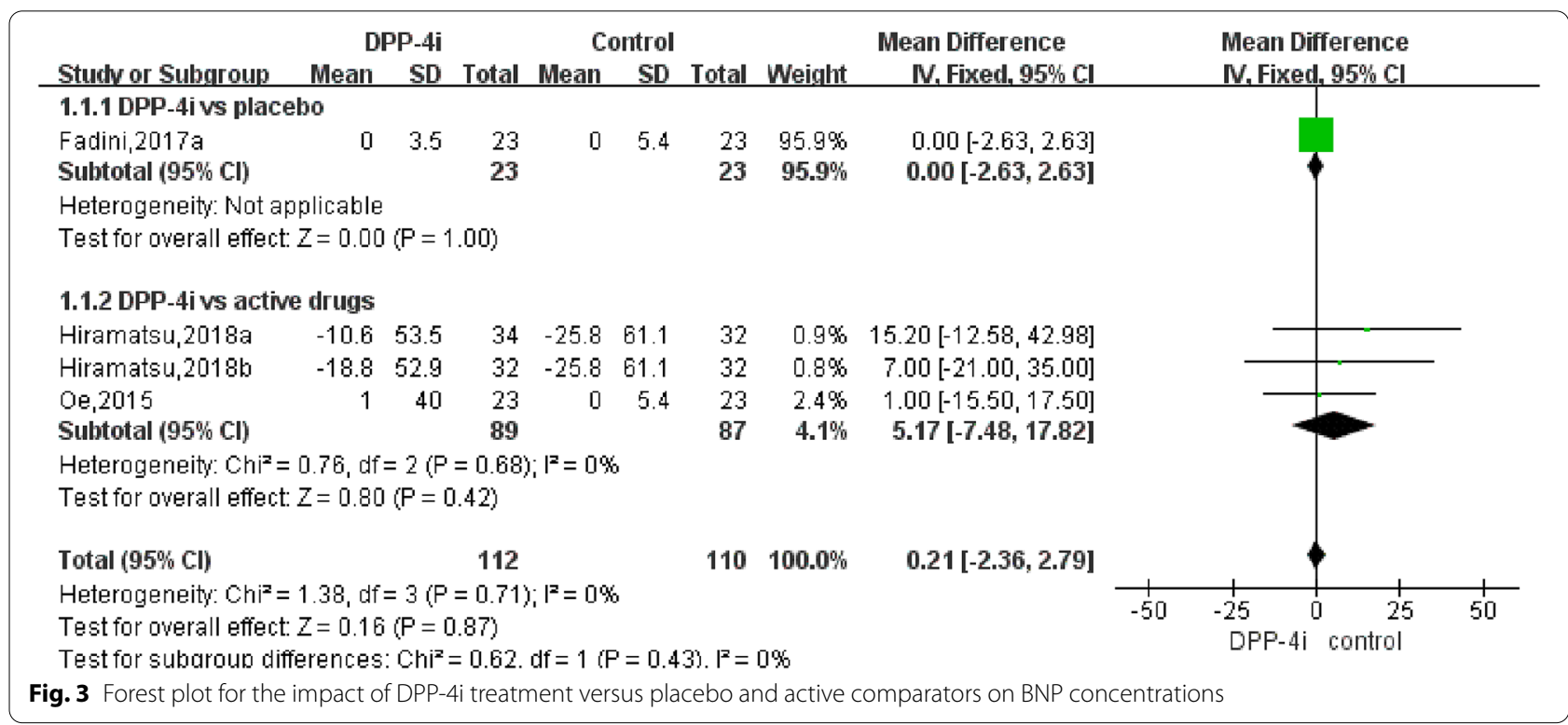

$\left.P=0.71, I^{2}=0 \%\right)$ and $5.17 \mathrm{pg} / \mathrm{mL}(95 \% \mathrm{CI}-7.48-17.82$, $\left.P=0.42, \mathrm{I}^{2}=0 \%\right)$ compared to traditional antidiabetic agents (Fig. 3). The pooled analysis of the effect of DPP-4is on NT-pro-BNP levels yielded a difference of $-7.34 \mathrm{pg} / \mathrm{mL}\left(95 \% \mathrm{CI}-24.27\right.$ to $\left.9.59, P=0.40, I^{2}=80 \%\right)$ and $-9.95 \mathrm{pg} / \mathrm{mL}$ (95\% CI - 44.61-24.71, $P=0.57$, $\left.\mathrm{I}^{2}=84 \%\right)$ compared to traditional antidiabetic agents (Fig. 4). The pooled estimate of the modulating effect of DPP-4is on NT-pro-BNP was credible in the leave1-out sensitivity analysis (WMD $-7.34 \mathrm{pg} / \mathrm{mL}, 95 \% \mathrm{CI}$ $-24.27,9.59, \mathrm{~N}=9$ studies, heterogeneity $P=0.395$; Fig. 5). This confirmed that the significant difference across the studies was an overall effect of all the identified studies. In the subgroup analysis, baseline HbA1c, length of follow-up and BMI did not influence the effect of DPP4is on NT-pro-BNP (Additional file 1: Figures S1-3). No publication bias was suggested by Begg's test $(P=0.62)$ or Egger's test $(P=0.86)$ across the 9 studies (Fig. 6).

\section{Discussion}

The current study investigated the hypothesis that DPP-4 inhibition does not present an impact on BNP and NTpro-BNP in T2DM. One important goal of antidiabetic agents in type 2 diabetes is to reduce cardiovascular complications and morbidity, in addition to lowering blood glucose levels. We found that DPP-4is did not significantly modulate BNP or NT-pro-BNP levels in T2DM compared to placebo or active antidiabetic agents.

BNP belongs to the natriuretic peptide family, which also includes atrial natriuretic peptide (ANP) and C-type natriuretic peptide (CNP). BNP binds to its receptor of natriuretic peptide type A receptor and exhibits a variety of actions, including vascular vasodilation and inhibition of renin secretion [19]. BNP is quickly metabolized to BNP 3-32 by DPP-4 in the plasma, which can be prevented by DPP-4is [20]. Under physiological conditions, plasma levels of BNP are low but increase in the pathophysiological state of heart failure. Administration of recombinant BNP effectively reduces afterload and exhibits a favorable effect on promoting natriuresis [21]. BNP can inhibit collagen synthesis and promote matrix metalloproteinase (MMP) activity through cGMP-PKG signaling, suggesting a role in regulating myocardial structure by modulating cardiac fibroblast function [22]. Plasma BNP activity seems to be absent in congestive heart failure [23]. It has been reported that BNP activity is modulated by DPP-4 in diabetic subjects with heart failure. DPP-4 activity is relatively high in patients with heart failure and thus modulates the pathophysiology of heart failure by acting on its substrate [24]. In fact, DPP-4 rapidly cleaves BNP $1-32$ to produce BNP $3-32$, and the latter shows reduced activity in modulating urinary sodium excretion and urine flow. However, the exact biological activity of BNP 3-32 remains uncertain. The two major subtypes of BNP in the plasma are BNP 1-32 and BNP 3-32, while we evaluated the change of total BNP levels before and after intervention in this study. Further studies will be needed to accurately determine the modulating effect of DPP-4is on different subtypes of BNP. DPP4-deficient rat models showed better cardiac performance, with a decrease in infarct size and cardiac injury biomarkers of BNP [25]. In another study, DPP-4 inhibition with vildagliptin or sitagliptin did not increase or decrease BNP levels in patients with T2DM [37]. 


\begin{tabular}{|c|c|c|c|c|c|c|c|c|c|c|c|c|}
\hline \multirow[b]{2}{*}{ Studv or Subigr oup } & \multicolumn{2}{|c|}{ DPP-4i } & & \multicolumn{2}{|c|}{ Control } & \multirow[b]{2}{*}{ Total } & \multirow[b]{2}{*}{ Weight } & \multicolumn{2}{|l|}{ Mean Differ ence } & \multirow{2}{*}{\multicolumn{2}{|c|}{$\begin{array}{c}\text { Mean Difference } \\
\text { N, Random, } 95 \% \text { CI }\end{array}$}} & \\
\hline & Mean & SD & Total & Mean & SD & & & IV, Random, 95\% Cl & & & & \\
\hline \multicolumn{13}{|c|}{ 2.1.1 DPP-4i vs placebo } \\
\hline Fadini,2017b & -3.5 & 15.6 & 23 & 2 & 20.8 & 23 & $19.7 \%$ & $-5.50[-16.13,5.13]$ & & & & \\
\hline Zannad, 2015 & -203 & 249.3 & 2701 & -196 & 226.2 & 2679 & $19.1 \%$ & $-17.00[-29.69,-4.31]$ & & & & \\
\hline Subtotal $(95 \% \mathrm{Cl})$ & & & 2724 & & & 2702 & $38.8 \%$ & $-10.71[-21.92,0.51]$ & & & & \\
\hline \multicolumn{13}{|c|}{$\begin{array}{l}\text { Heterogeneity: Tau }{ }^{2}=30.47 ; \mathrm{Chi}^{2}=1.85, \mathrm{df}=1(\mathrm{P}=0.17) ; \mathrm{F}^{2}=46 \% \\
\text { Test for overal effect: } Z=1.87(\mathrm{P}=0.06)\end{array}$} \\
\hline \multicolumn{13}{|c|}{ 2.1.2 DPP-4i vs active drugs } \\
\hline Arturi,2016a & -7 & 41.7 & 10 & -87 & 80.8 & 10 & $6.3 \%$ & $80.00[23.64,136.36]$ & & & & \\
\hline Arturi,2016b & -7 & 41.7 & 10 & 20 & 54.3 & 12 & $9.7 \%$ & $-27.00[-67.15,13.15]$ & $\longleftarrow$ & & & \\
\hline Kitao,2017 & -5 & 117.7 & 46 & -2 & 61.7 & 43 & $10.1 \%$ & $-3.00[-41.69,35.69]$ & & & & \\
\hline Nomoto,2016 & -1 & 21.9 & 41 & -2 & 22.4 & 49 & $20.1 \%$ & $1.00[-8.18,10.18]$ & & & & \\
\hline Phrommintikul,2019 & -518.5 & 396.7 & 22 & -124.12 & 81.6 & 21 & $1.0 \%$ & $-394.38[-563.78,-224.98]$ & 4 & & & \\
\hline Yamada,2017 & 3 & 68.1 & 55 & 14.5 & 75.6 & 55 & $13.9 \%$ & $-11.50[-38.39,15.39]$ & & & & \\
\hline Subtotal $(95 \% \mathrm{Cl})$ & & & 184 & & & 190 & $61.2 \%$ & $-9.95[-44.61,24.71]$ & & & & \\
\hline \multicolumn{13}{|c|}{$\begin{array}{l}\text { Heterogeneity: } \text { Tau }^{2}=1293.98 ; \mathrm{Chi}^{2}=31.04, \mathrm{df}=5(\mathrm{P}=0.00001) ; \mathrm{I}^{2}=94 \% \\
\text { Test for overall effect: } Z=0.56(\mathrm{P}=0.57)\end{array}$} \\
\hline Total $(95 \% \mathrm{Cl})$ & & & 2908 & & & 2892 & $100.0 \%$ & $-7.34[-24.27,9.59]$ & & & & \\
\hline \multicolumn{9}{|c|}{$\begin{array}{l}\text { Heterogeneity: Tau }=348.80 ; \mathrm{Chi}^{2}=35.48, \mathrm{df}=\mathrm{T}(\mathrm{P}=0.00001) ; \mathrm{I}^{2}=80 \% \\
\text { Test for owerall effect: } Z=0.85(\mathrm{P}=0.40) \\
\text { Test for subaroun differences: } \mathrm{Chi}^{2}=0.00 . \mathrm{df}=1(\mathrm{P}=0.97) . \mathrm{F}^{2}=0 \%\end{array}$} & -50 & -25 & $0 \quad 25$ & 50 \\
\hline
\end{tabular}

BNP concentrations are reduced in people with obesity, insulin resistance, and diabetes, and this deficiency may contribute to their cardiovascular risk [13]. The $\mathrm{N}$-terminal pro-brain natriuretic peptide (NT-pro-BNP) is biologically inert and is secreted in the plasma, like BNP. BNP and NT-pro-BNP are used in the diagnosis of congestive heart failure in elderly individuals and seem to have comparable diagnostic value [26]. Elevation of NT-pro-BNP levels shows a strong correlation with a poor prognosis of elderly chronic heart failure patients [27]. Plasma levels of NT-pro-BNP also increase in obese and diabetic patients, which might be related to chronic

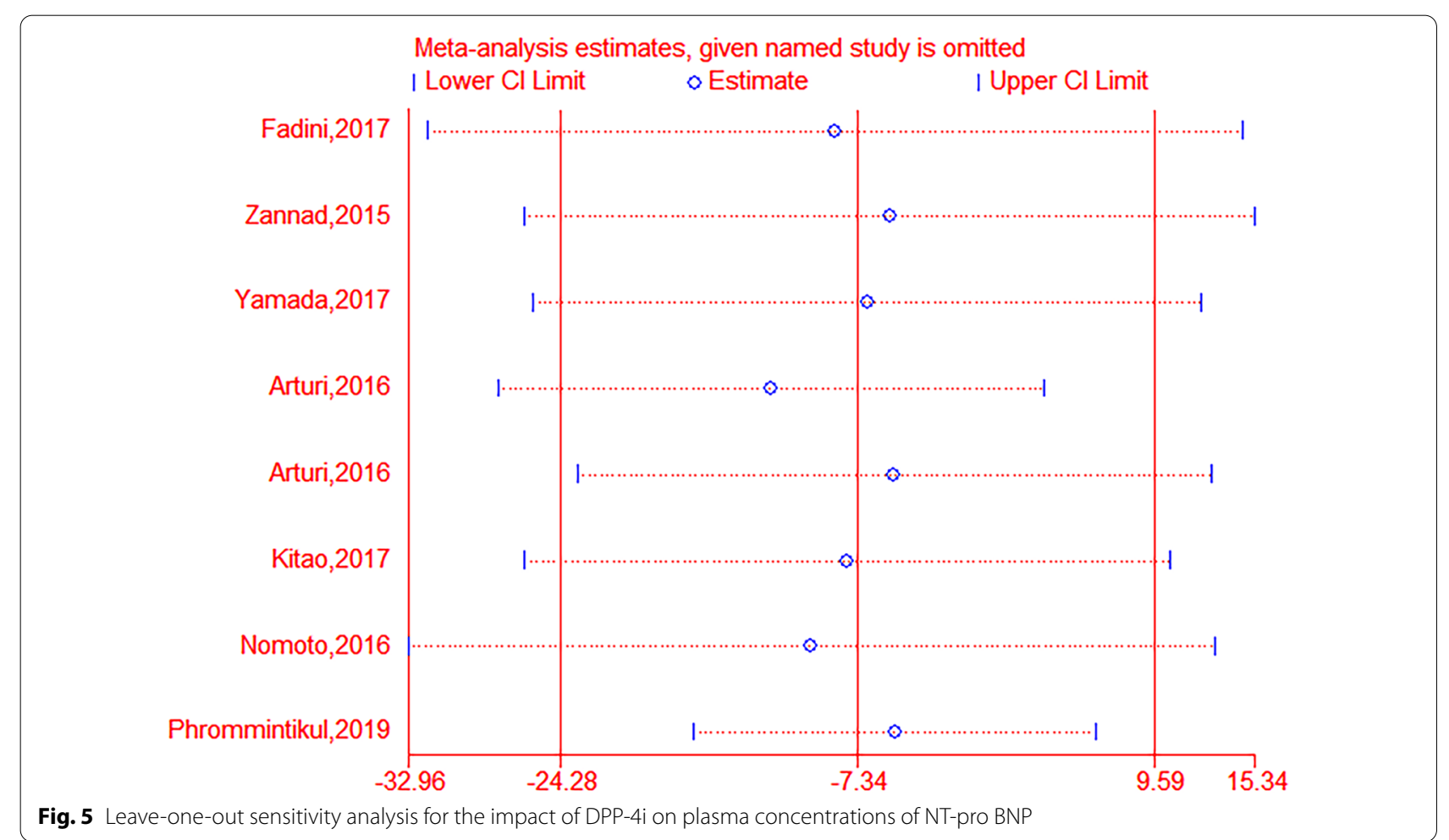


Begg's funnel plot with pseudo 95\% confidence limits

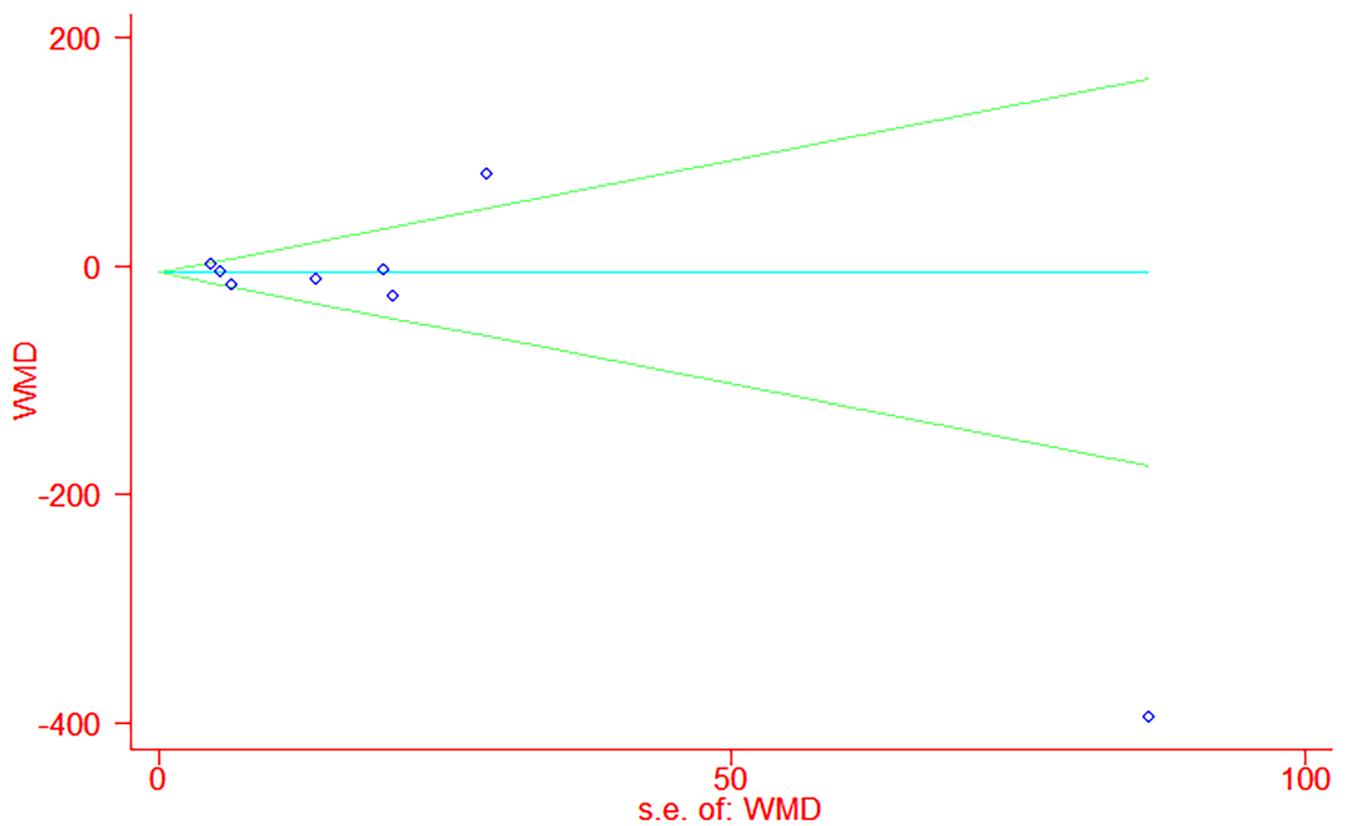

Fig. 6 Assessment of publication bias in the meta-analysis of studies reporting the impact of DPP-4i on plasma concentrations of NT-pro BNP

low-grade inflammation and insulin resistance [28]. NTpro-BNP concentrations are affected by the presence of comorbidities such as T2DM and acute coronary syndrome. Serial monitoring of NT-pro-BNP might be useful for identifying patients with a higher risk of heart failure in patients with T2DM and ischemic heart diseases [29]. NT-pro-BNP is a better short-term independent predictor of cardiovascular mortality than $\mathrm{C}$-reactive protein and albumin excretion rate in elderly patients with T2DM, according to the Casale Monferrato population-based study [30].

Under pathological conditions, the mRNA encoding BNP can rapidly synthesize BNP precursor (pre-proBNP) and be split into NT-pro-BNP [31]. Although a number of studies have been carried out to investigate the effect of DPP-4is on modulating BNP and NT-proBNP in diabetes, no firm conclusions have been drawn. Compared to conventional antidiabetic regimens, add-on sitagliptin treatment showed no significant difference in changing plasma levels of NT-pro-BNP according to the subanalysis of the PROLOGUE study [17]. In another study, DPP-4 inhibition with vildagliptin or sitagliptin did not increase or decrease BNP levels in T2DM patients [37]. In a multicenter, randomized, double-blind trial, alogliptin presented no significant effect on the composite event of cardiovascular death and hospital administration among heart failure in patients with T2DM. However, plasma levels of NT-pro-BNP decreased significantly after treatment with alogliptin [18]. Our results are consistent with a previous study, in which sitagliptin did not regulate vascular function by affecting the degradation of GLP-1 and BNP in healthy participants [32]. Moreover, in a preclinical study, DPP-4is seemed to downregulate the level of neprilysin, thus reducing the degradation of BNP and ANP [33]. However, in another randomized cross-over trial in patients with T2DM, acute treatment with linagliptin led to no significant change in BNP or NT-pro-BNP level compared to placebo in patients with or without chronic kidney disease. This suggested that changes in NT-pro-BNP over the long run most likely reflect the natural history of heart failure rather than an effect of antidiabetic treatment [13].

DPP4i-treated T2DM patients had lower risks for cardiovascular events, including heart failure, myocardial infarction and ischemic stroke, than non-DPP4i users [34]. In the SAVOR-TIMI 53 study, saxagliptin was found to be correlated with an increased risk of hospitalization for heart failure [35]. However, no increased risk of hospitalization for heart failure was found in patients treated with DPP-4is through an analysis of Taiwan's National Health Insurance claims database, which included a total of 239,669 T2DM patients treated with sitagliptin, saxagliptin or vildagliptin from 2011 to 2013. Three DPP-4is have been proven to be safe in terms of the risk of heart failure at present. Saxagliptin had a similar risk (HR: 0.98, 95\% CI 0.91-1.06) as sitagliptin, while vildagliptin was associated with a lower risk of heart failure (HR: 0.85, 95\% CI 078-0.93) [36]. In another observational study including 962 
hospitalized heart failure patients, DPP-4is seemed to improve cardiac and all-cause mortality in hospitalized heart failure patients with diabetes mellitus [37]. According to a pooled meta-analysis including 90 randomized clinical trials, DPP-4is showed a similar safety profile as placebo in patients with type 2 diabetes. There was only weak evidence for an increased risk of heart failure [38].

The current study is the first pooled analysis demonstrating the effect of DPP-4is on serum BNP and NTpro-BNP concentrations in patients with T2DM. We performed a sensitivity analysis on the included trials and surprisingly found that DPP-4is caused no significant increase in the plasma level of BNP or NT-pro-BNP.

Our study might have some limitations. First, the methods of measuring BNP or NT-pro-BNP might be different in each study, which could cause an inevitable bias. Second, the studies had differences in the baseline BNP or NT-pro-BNP values in patients with T2DM and in whether they had received cardiovascular therapy, which also could have had an effect on the pooled analysis. Third, few trials were included in the pooled analysis, which could cause a publication bias. Further studies with more trials should be performed to verify any associations between DPP-4is and BNP/NT-pro-BNP. Fourth, we only investigated the impact of DPP-4is on BNP/NTpro-BNP concentrations, while the effect of DPP-4is on the other biomarkers of heart failure should be explored with further studies. Last, the impact of DPP-4is on BNP and NT-pro-BNP in the long run should also be taken into consideration, which should be studied in trials with long-term DPP-4i treatment.

\section{Conclusions}

In conclusion, DPP-4is have no significant effects on the BNP or NT-pro-BNP level in patients with T2DM. These agents are relatively well tolerated when used as monotherapy or in combination with traditional antidiabetic agents in diabetes. Data on long-term effects are needed in patients with T2DM with risks of cardiovascular disease, such as heart failure. In addition, BNP and NT-proBNP monitoring should be done in T2DM patients with cardiovascular disease who take antidiabetic agents such as DPP-4is.

\footnotetext{
Abbreviations

DPP-4is: Dipeptidyl peptidase-4 inhibitors; T2DM: Type 2 diabetes mellitus; RCTs: Randomized controlled trials; BNP: Brain natriuretic peptide; NT-pro BNP: N-terminal probrain natriuretic peptide; CVD: Cardiovascular disease; $\mathrm{Cl}$ : Confidence intervals; SD: Standard deviations; WMD: Weighted mean difference; GLP-1: Glucagon-like peptide 1; GIP: Glucose-dependent insulinotropic polypeptide; ANP: Atrial natriuretic peptide; CNP: C-type natriuretic peptide
}

(CNP); MMP: Matrix metalloproteinase; BNP: Brain natriuretic peptide; NT-pro BNP: N-terminal probrain natriuretic peptide.

\section{Supplementary Information}

The online version contains supplementary material available at https://doi. org/10.1186/s13098-022-00797-x.

Additional file 1: Figure S1. Forest plot for the impact of DPP-4i treatment versus comparators on serum concentrations of NT-pro BNP in subgroups of trials with $\mathrm{HbA} 1 \mathrm{c}$ levels of $<8.0 \%$ and $\geq 8.0 \%$.

Additional file 2: Figure S2. Forest plot for the impact of DPP-4i treatment versus comparators on serum concentrations of NT-pro BNP in subgroups of trials with treatment durations of $<6$ months and $\geq 6$ months.

Additional file 3: Figure S3. Forest plot for the impact of DPP-4i treatment versus comparators on serum concentrations of NT-pro BNP in subgroups of trials with ages of $<60$ years and 60 years.

\section{Acknowledgements}

We would like to thank Dr. Lvya Wang of the Department of Cardiology, Capital Medical University for her advice and suggestions relating to this manuscript.

\section{Authors' contributions}

$L M, Z W, J R, X X, Z J$ and $X L$ participated in the design, conduct and collection of this meta-analysis. ZW and XX searched the literature, extracted the data and evaluated risk of bias. All the authors took part in writing the manuscript. ZJ and $X \mathrm{~L}$ have full access to all the data, and take full responsibility for the integrity of the data analysis. All authors read and approved the final manuscript.

\section{Funding}

This work is supported in part by Beijing Hospitals Authority Youth Program (No. QML20170507) and Cultivation Research Program (No. PYZ19099) of China awarded to X. Liu.

\section{Availability of data and materials}

All data generated or analyzed during this study are included in this published article (and its Additional files).

\section{Declarations}

Ethics approval and consent to participate

Not applicable.

Consent for publication

Not applicable.

\section{Competing interests}

The authors declare that they have no competing interests.

\section{Author details}

'Department of Cardiology, Beijing Tiantan Hospital, Capital Medical University, Beijing, China. ${ }^{2}$ Department of Gastroenterology, Beijing Tiantan Hospital, Capital Medical University, Beijing, China. ${ }^{3}$ Department of Pharmacy, Qingpu Branch of Zhongshan, Fudan University, Shanghai, China. ${ }^{4}$ Department of Pharmacy, Beijing Tiantan Hospital, Capital Medical University, Beijing, China. ${ }^{5}$ Department of Cardiology and Macrovascular Disease, Beijing Tiantan Hospital, Capital Medical University, Beijing, China.

Received: 10 November 2021 Accepted: 20 January 2022

Published online: 14 February 2022

\section{References}

1. Mikov M, Pavlović N, Stanimirov B, Đanić M, Goločorbin-Kon S, Stankov K, Al-Salami H. DPP-4 inhibitors: renoprotective potential and 
pharmacokinetics in type 2 diabetes mellitus patients with renal impairment. Eur J Drug Metab Pharmacokinet. 2020;45:1-14.

2. Deacon CF, Lebovitz HE. Comparative review of dipeptidyl peptidase-4 inhibitors and sulphonylureas. Diabetes Obes Metab. 2016;18:333-47.

3. Lebovitz HE. Thiazolidinediones: the forgotten diabetes medications. Curr Diab Rep. 2019;19:151.

4. Zhu J, Yu X, Zheng Y, Li J, Wang Y, Lin Y, He Z, Zhao W, Chen C, Qiu K, Wu J. Association of glucose-lowering medications with cardiovascular outcomes: an umbrella review and evidence map. Lancet Diabetes Endocrinol. 2020;8:192-205.

5. Nauck MA, Meier JJ, Cavender MA, AbdEIAziz M, Drucker DJ. Cardiovascular actions and clinical outcomes with glucagon-like peptide-1 receptor agonists and dipeptidyl peptidase-4 inhibitors. Circulation. 2017;136:849-70.

6. Scirica BM, Braunwald E, Raz I, Cavender MA, Morrow DA, Jarolim P, Udell JA, Mosenzon O, Im K, Umez-Eronini AA, et al. Heart failure, saxagliptin, and diabetes mellitus: observations from the SAVOR-TIMI 53 randomized trial. Circulation. 2014;130:1579-88.

7. Hocher B, Reichetzeder C, Alter ML. Renal and cardiac effects of DPP4 inhibitors-from preclinical development to clinical research. Kidney Blood Press Res. 2012;36:65-84.

8. Cao Z, Jia Y, Zhu B. BNP and NT-proBNP as diagnostic biomarkers for cardiac dysfunction in both clinical and forensic medicine. Int J Mol Sci. 2019. https://doi.org/10.3390/ijms20081820.

9. Liberati A, Altman DG, Tetzlaff J, Mulrow C, Gøtzsche PC, loannidis JP, Clarke M, Devereaux PJ, Kleijnen J, Moher D. The PRISMA statement for reporting systematic reviews and meta-analyses of studies that evaluate healthcare interventions: explanation and elaboration. BMJ. 2009;339:b2700.

10. Oe H, Nakamura K, Kihara H, Shimada K, Fukuda S, Takagi T, Miyoshi T, Hirata K, Yoshikawa J, Ito H. Comparison of effects of sitagliptin and voglibose on left ventricular diastolic dysfunction in patients with type 2 diabetes: results of the 3D trial. Cardiovasc Diabetol. 2015;14:83.

11. Hiramatsu T, Asano Y, Mabuchi M, Imai K, Iguchi D, Furuta S. Liraglutide relieves cardiac dilated function than DPP-4 inhibitors. Eur J Clin Invest. 2018:48:e13007.

12. Arturi F, Succurro E, Miceli S, Cloro C, Ruffo M, Maio R, Perticone M, Sesti G, Perticone F. Liraglutide improves cardiac function in patients with type 2 diabetes and chronic heart failure. Endocrine. 2017;57:464-73.

13. Fadini GP, Bonora BM, Albiero M, Zaninotto M, Plebani M, Avogaro A. DPP-4 inhibition has no acute effect on BNP and its N-terminal pro-hormone measured by commercial immune-assays. A randomized cross-over trial in patients with type 2 diabetes. Cardiovasc Diabetol. 2017;16:22.

14. Kitao N, Miyoshi H, Furumoto T, Ono K, Nomoto H, Miya A, Yamamoto C, Inoue A, Tsuchida K, Manda N, et al. The effects of vildagliptin compared with metformin on vascular endothelial function and metabolic parameters: a randomized, controlled trial (Sapporo Athero-Incretin Study 3). Cardiovasc Diabetol. 2017;16:125.

15. Nomoto H, Miyoshi H, Furumoto T, Oba K, Tsutsui H, Inoue A, Atsumi T, Manda N, Kurihara Y, Aoki S. a randomized controlled trial comparing the effects of sitagliptin and glimepiride on endothelial function and metabolic parameters: Sapporo Athero-Incretin Study 1 (SAIS1). PLoS ONE. 2016;1 :e0164255.

16. Phrommintikul A, Wongcharoen W, Kumfu S, Jaiwongkam T, Gunaparn S, Chattipakorn S, Chattipakorn N. Effects of dapagliflozin vs vildagliptin on cardiometabolic parameters in diabetic patients with coronary artery disease: a randomised study. Br J Clin Pharmacol. 2019;85:1337-47.

17. Yamada H, Tanaka A, Kusunose K, Amano R, Matsuhisa M, Daida H, Ito M, Tsutsui $H$, Nanasato M, Kamiya H, et al. Effect of sitagliptin on the echocardiographic parameters of left ventricular diastolic function in patients with type 2 diabetes: a subgroup analysis of the PROLOGUE study. Cardiovasc Diabetol. 2017;16:63.

18. Zannad F, Cannon CP, Cushman WC, Bakris GL, Menon V, Perez AT, Fleck PR, Mehta CR, Kupfer S, Wilson C, et al. Heart failure and mortality outcomes in patients with type 2 diabetes taking alogliptin versus placebo in EXAMINE: a multicentre, randomised, double-blind trial. Lancet. 2015;385:2067-76.

19. Tsuruda T, Boerrigter G, Huntley BK, Noser JA, Cataliotti A, Costello-Boerrigter $\mathrm{LC}$, Chen $\mathrm{HH}$, Burnett JC Jr. Brain natriuretic peptide is produced in cardiac fibroblasts and induces matrix metalloproteinases. Circ Res. 2002;91:1127-34

20. Gomez N, Touihri K, Matheeussen V, Da Costa AM, Mahmoudabady M, Mathieu M, Baerts L, Peace A, Lybaert P, Scharpé S, et al. Dipeptidyl peptidase IV inhibition improves cardiorenal function in overpacinginduced heart failure. Eur J Heart Fail. 2012;14:14-21.

21. Munagala VK, Burnett JC Jr, Redfield MM. The natriuretic peptides in cardiovascular medicine. Curr Probl Cardiol. 2004;29:707-69.

22. Abbas SS, Mahmoud HM, Schaalan MF, El-Abhar HS. Involvement of brain natriuretic peptide signaling pathway in the cardioprotective action of sitagliptin. Pharmacol Rep. 2018;70:720-9.

23. Huntley BK, IChiki T, Sangaralingham SJ, Chen HH, Burnett JC Jr. B-type natriuretic peptide and extracellular matrix protein interactions in human cardiac fibroblasts. J Cell Physiol. 2010;225:251-5.

24. Pala L, Rotella CM. The role of DPP4 activity in cardiovascular districts: in vivo and in vitro evidence. J Diabetes Res. 2013;2013:590456.

25. Ku HC, Chen WP, Su MJ. DPP4 deficiency preserves cardiac function via GLP-1 signaling in rats subjected to myocardial ischemia/reperfusion. Naunyn Schmiedebergs Arch Pharmacol. 2011;384:197-207.

26. El Mahmoud R, Alibay Y, Brun-Ney D, Boulard JC, Dubourg O, Puy H, Jondeau G. Type B natriuretic peptide (BNP) versus n-terminal type B natriuretic propeptide in the diagnosis of cardiac failure in the elderly over 75 population. Arch Mal Coeur Vaiss. 2006;99:201-7.

27. Shi L, Zhang Y, Zhang J, Gao Y, Liu J, Chen M, Yang X. Application of blood pre-albumin and NT-pro BNP levels in evaluating prognosis of elderly chronic heart failure patients. Exp Ther Med. 2020;20:1337-42.

28. Baldassarre S, Fragapani S, Panero A, Fedele D, Pinach S, Lucchiari M, Vitale AR, Mengozzi G, Gruden G, Bruno G. NTproBNP in insulin-resistance mediated conditions: overweight/obesity, metabolic syndrome and diabetes. The population-based Casale Monferrato Study. Cardiovasc Diabetol. 2017;16:119.

29. Jarolim P, White WB, Cannon CP, Gao Q, Morrow DA. Serial measurement of natriuretic peptides and cardiovascular outcomes in patients with type 2 diabetes in the EXAMINE trial. Diabetes Care. 2018;41:1510-5.

30. Bruno G, Landi A, Barutta F, Ghezzo G, Baldin C, Spadafora L, Schimmenti A, Prinzis T, Cavallo Perin P, Gruden G. N-terminal probrain natriuretic peptide is a stronger predictor of cardiovascular mortality than C-reactive protein and albumin excretion rate in elderly patients with type 2 diabetes: the Casale Monferrato population-based study. Diabetes Care. 2013;36:2677-82

31. Kerkelä R, Ulvila J, Magga J. Natriuretic peptides in the regulation of cardiovascular physiology and metabolic events. J Am Heart Assoc. 2015;4:e002423.

32. Devin JK, Pretorius M, Nian H, Yu C, Billings FTT, Brown NJ. Dipeptidylpeptidase 4 inhibition and the vascular effects of glucagon-like peptide-1 and brain natriuretic peptide in the human forearm. J Am Heart Assoc. 2014. https://doi.org/10.1161/JAHA.114.001075.

33. Kawase H, Bando YK, Nishimura K, Aoyama M, Monji A, Murohara T. A dipeptidyl peptidase-4 inhibitor ameliorates hypertensive cardiac remodeling via angiotensin-II/sodium-proton pump exchanger-1 axis. J Mol Cell Cardiol. 2016;98:37-47.

34. Ou HT, Chang KC, Li CY, Wu JS. Risks of cardiovascular diseases associated with dipeptidyl peptidase-4 inhibitors and other antidiabetic drugs in patients with type 2 diabetes: a nation-wide longitudinal study. Cardiovasc Diabetol. 2016;15:41.

35. Scirica BM, Bhatt DL, Braunwald E, Steg PG, Davidson J, Hirshberg B, Ohman P, Frederich R, Wiviott SD, Hoffman EB, et al. Saxagliptin and cardiovascular outcomes in patients with type 2 diabetes mellitus. N Engl J Med. 2013;369:1317-26.

36. Chang CH, Chang YC, Lin JW, Caffrey JL, Wu LC, Lai MS, Chuang LM. No increased risk of hospitalization for heart failure for patients treated with dipeptidyl peptidase-4 inhibitors in Taiwan. Int J Cardiol. 2016;220:14-20.

37. Sato A, Yoshihisa A, Kanno Y, Takiguchi M, Miura S, Shimizu T, Nakamura Y, Yamauchi H, Owada T, Sato T, et al. Associations of dipeptidyl peptidase-4 inhibitors with mortality in hospitalized heart failure patients with diabetes mellitus. ESC Heart Fail. 2016;3:77-85.

38. Elgendy IY, Mahmoud AN, Barakat AF, Elgendy AY, Saad M, Abuzaid A, Wayangankar SA, Bavry AA. Cardiovascular safety of dipeptidyl-peptidase IV inhibitors: a meta-analysis of placebo-controlled randomized trials. Am J Cardiovasc Drugs. 2017;17:143-55.

\section{Publisher's Note}

Springer Nature remains neutral with regard to jurisdictional claims in published maps and institutional affiliations. 